\title{
MODIS-based multi-parametric platform for mapping of flood affected areas. Case study: 2006 Danube extreme flood in Romania
}

\author{
Vasile Craciunescu $^{1 *}$, Gheorghe Stancalie ${ }^{1}$, Anisoara Irimescu ${ }^{1}$, Simona Catana $^{1}$, Denis Mihailescu ${ }^{1}$, \\ Argentina Nertan ${ }^{1}$, George $\operatorname{Morcov}^{1}$, Stefan Constantinescu ${ }^{2}$ \\ ${ }^{1}$ National Meteorological Administration 97, Soseaua Bucuresti-Ploiesti, sector 1 013686, Bucharest, Romania.
2 Faculty of Geography, University of Bucharest 1, Bd. Nicolae Bălcescu, Sector 1, Bucharest, Romania.
${ }^{*}$ Corresponding author. Tel.: +40-21-316 60 98. Fax: $+40-21-31660$ 98. E-mail: vasile.craciunescu@meteoromania.ro
}

\begin{abstract}
Flooding remains the most widely distributed natural hazard in Europe, leading to significant economic and social impact. Earth observation data is presently capable of making fundamental contributions towards reducing the detrimental effects of extreme floods. Technological advance makes development of online services able to process high volumes of satellite data without the need of dedicated desktop software licenses possible. The main objective of the case study is to present and evaluate a methodology for mapping of flooded areas based on MODIS satellite images derived indices and using state-of-the-art geospatial web services. The methodology and the developed platform were tested with data for the historical flood event that affected the Danube floodplain in 2006 in Romania. The results proved that, despite the relative coarse resolution, MODIS data is very useful for mapping the development flooded area in large plain floods. Moreover it was shown, that the possibility to adapt and combine the existing global algorithms for flood detection to fit the local conditions is extremely important to obtain accurate results.
\end{abstract}

Keywords: Flood extent mapping; MODIS; Web services; 2006 Danube Flood.

\section{INTRODUCTION}

Flood risk management is the result of an extensive combination of preventive pre crisis actions, operational actions during the event and post crisis actions of restoration and recovery. Traditional measures to reduce negative impacts of floods include constructing new or reinforcing existing flood defence infrastructure such as dykes and dams. There are, however, other and potentially very cost-effective methods to achieve flood protection which profit from nature's own capacity to absorb excess waters (European Commission, 2003; 2011; 2014). Nature-based solutions, such as improving land-use to prevent rapid run-off, taking advantage of natural infiltration capacities and mobilizing floodplains having storage capacities allows reducing or mitigating flood impact (McIntyre and Thorne, 2013). This approach could also be successfully used for Danube. Over the last 150 years the landscape of the Danube River floodplain changed dramatically. Most of the large alluvial plains, mixed with marshlands and small lakes, along the Romanian side of Danube, have been affected by river embankments, drainage systems and urban sprawling. As a consequence, an important strip of land (width ranges from 1 to $10 \mathrm{~km}$ in our study area), once a wetland prone to floods, was converted to arable land (Craciunescu et al., 2010). The radical transformation of the Danube floodplain affected not only the region, but also the mindset of the local population (Constantinescu et al, 2015). After the 2006 historical flood, the subject of renaturation (ecological restoration) of the Danube floodplains gains significant importance in Romania (Nichersu, 2009). In this context, satellite imagery can be very effective for detailed flood mapping activities, for understanding the impact of floods and for providing objective information to experts and decision makers involved in developing plans for the future development of the Danube floodplains.

There are several methods of identifying flooded areas using microwave and optical remote sensing imagery (Jensen, 2015; Schuman et al., 2009). Optical instruments such as Moderate
Resolution Imaging Spectroradiometer (MODIS) on board of NASA's Terra and Aqua satellites offer a unique combination of quasi-global daily coverage with acceptable spatial resolution $(250 \mathrm{~m}, 500 \mathrm{~m}$ and $1 \mathrm{~km}$ spatial resolution bands). These capabilities are being utilized for flood monitoring at regional and global scales.

Previous studies demonstrated that MODIS data can be used to distinguish between flooded and non-flooded areas with suitable spatial resolution (Brakenridge et al., 2003). MODIS data has the advantage of global coverage, and so can be available worldwide (Sun et al., 2010). The suitability of medium spatial resolution, high-temporal resolution and multi-spectral imagery like MODIS for large flood mapping was demonstrated by a number of studies (Islam et al., 2009; Kawak and Iwami, 2014; Kugler and De Groeve, 2007; Park and Kwak, 2011). However, in combination with other high resolution satellite data, like Topex/Poseidon and Envisat (Crétaux et al., 2011), ALOS (Amarnath and Rajah, 2015) or LANDSAT (Phuong et al., 2015), MODIS imagery was successfully used to map medium to small flood events. MODIS sensors are also able to provide useful information for hydrodynamic modelling at large regional/basin scales (Ticehurst et al., 2013). The German Aerospace Center (DLR) developed an automated flood monitoring system that is using MODIS data to detect potential flood events on a continental scale and derives flood information in combination with the high resolution Synthetic Aperture Radar (SAR) data provided by TerraSAR-X satellite (Martinis et al., 2013). A more recent study (Coltin et al., 2016) demonstrated the feasibility of an effective automatic flood mapping system using MODIS imagery and machine learning algorithms.

A number of initiatives such as the International Charter on Space and Major Disasters (Bessisa et al, 2004), Copernicus Emergency Management Service (Copernicus EMS-Mapping, 2012), United Nations Platform for Space-based Information for Disaster Management and Emergency Response (UN SPIDER, 2006), Global Land Cover Facility MODIS Flood Maps (GLCF MODIS Flood Maps, 2008), NRT Global Flood Mapping 


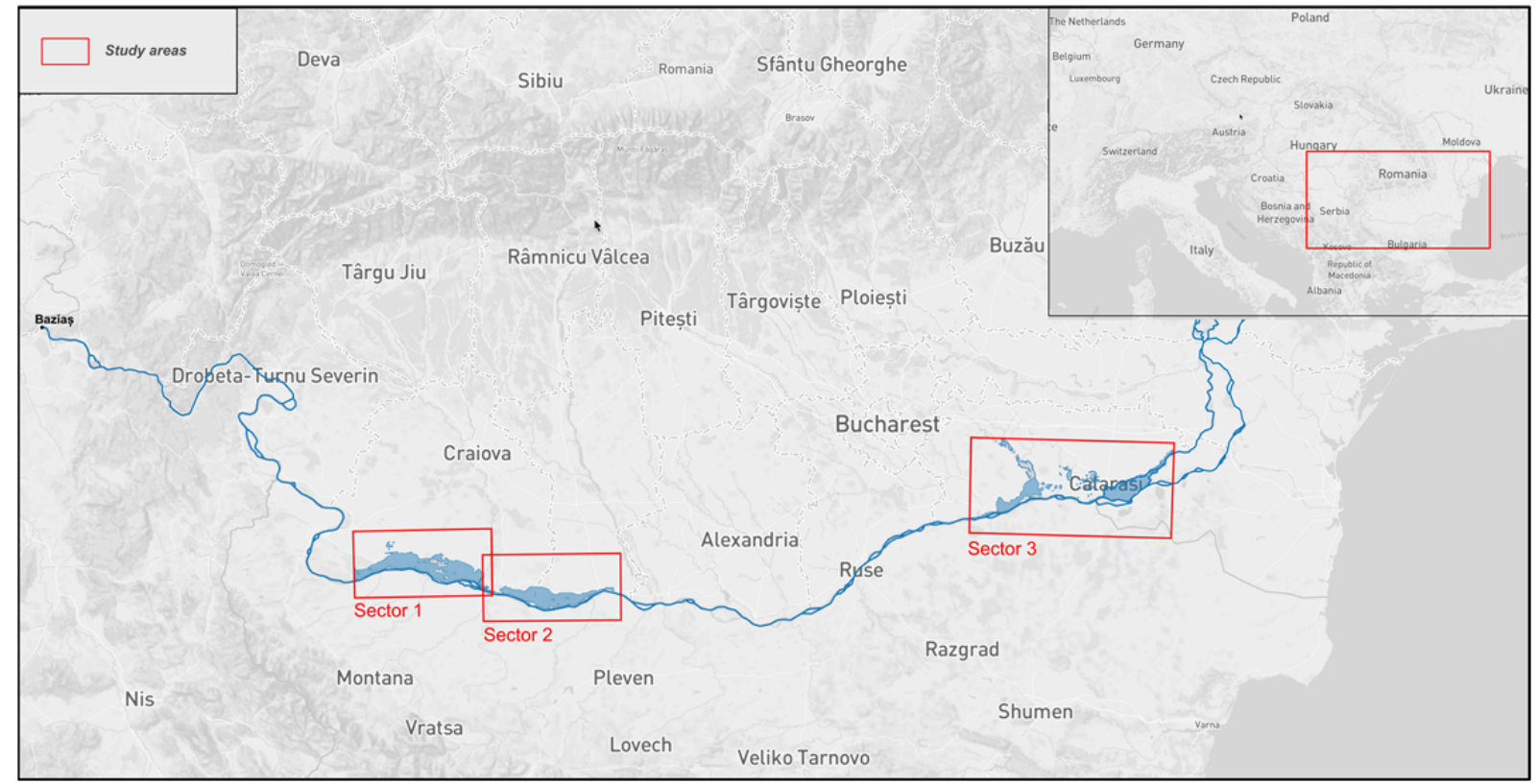

Fig. 1. Study areas (from West to East: Sector 1 Ghidici-Măceșu; Sector 2 Bechet-Corabia and Sector 3 Oltenița-Călărași).

(Nigro et al., 2014), are also using MODIS space-based information in support of flood monitoring.

All these services offer unified systems of satellite data acquisition and delivery to the countries affected by floods and other natural or man-made disasters, with a worldwide coverage. However, the results are not calibrated for local conditions and they offer no possibility for researchers to adjust the algorithms variables to fit the local conditions. This is a problem in countries like Romania where, due to historical reasons, the land fragmentation is very high, making the global water delineation algorithms to perform weak due to the complexity of the flooded terrain and of the surrounding areas.

The main objective of this study is to propose and validate a methodology for mapping of flooded areas based on MODIS satellite images derived indices. The methodology is implemented in the form of a web service platform, which is based on open source software and open standards. This allows the users to assess and evaluate flood extent areas without downloading a large amount of satellite data to a local machine.

The methodology is tested for extreme flood along the Romanian side of Danube in 2006. Validation is based on high resolution ASTER satellite images (Figure 1). ASTER (Advanced Spaceborne Thermal Emission and Reflection Radiometer) is a key sensor aboard Terra, the same satellite platform which hosts MODIS sensor, having the advantage of capturing images in the same time as MODIS. The ground resolutions of the 14 spectral bands allow flood extent mapping with 15, 30, and $90 \mathrm{~m}$ spatial resolution, respectively (Yamaguchi et al., 1998).

\section{EXTREME DANUBE FLOOD IN 2006}

The Danube flood of April-May 2006 was the greatest flood event registered on the Romanian sector of Danube in the last 150 years, having the maximum discharge/stages as well as the longest duration of water stage, over the inundation thresholds (Romanian Ministry of Environment and Water Management, 2006). A combined effect of snow melt with liquid precipitation in the upper and central part of the basin and closely saturated soils leaded to record peak water levels and discharge on Danube (e.g. $15800 \mathrm{~m}^{3} / \mathrm{s}$ at Baziaș, compared with $7900 \mathrm{~m}^{3} / \mathrm{s}$, the multiannual average discharge value of April) and most of the important tributaries in upper, central and lower basin (e.g. Tisza $-3790 \mathrm{~m}^{3} / \mathrm{s}$; Sava $-4470 \mathrm{~m}^{3} / \mathrm{s}$; Velika Morava $1740 \mathrm{~m}^{3} / \mathrm{s}$; Jiu $1020 \mathrm{~m}^{3} / \mathrm{s}$; Siret $1200 \mathrm{~m}^{3} / \mathrm{s}$ ). The return period of these peak discharges is approximately 100 years. (Wachter et al., 2008). The registered levels induced longitudinal dike failures in several locations along the Romanian sector of Danube, causing important losses. More than 15000 people were evacuated and some of the affected areas remained flooded for many years.

\section{FLOOD MAPPING METHODOLOGY \\ Data sources}

Two types of freely available satellite images, covering the period April-December 2006, were acquired and uploaded on the on line platform: (1) Daily Terra MODIS surface spectral reflectance MODIS products (MOD09GQ for $250 \mathrm{~m}$ bands 1-2 and MOD09GA for $1 \mathrm{~km}$ and $500 \mathrm{~m}$ bands) were automatically downloaded from NASA FTP servers using a Python library called pyModis; and (2) Cloud free ASTER, LANDSAT 5 and LANDSAT 7 images downloaded from the USGS GLOVIS portal. Unfortunately, due to cloud cover and relatively low temporal resolution, only a few suitable ASTER and LANDSAT scenes could be used. However, the information was very useful for validation purposes.

A number of reference datasets were also integrated into the online analysis platform. The list includes historical maps (used to reconstruct the pre-embanking landscape), topographical maps, aerial images (2005), reference water masks (pre-flood situation), digital elevation model, soil maps, land cover/use maps, GIS layers (localities, transportation network, points of interest, etc.).

\section{Image pre-processing}

MODIS data is provided by NASA as HDF-EOS grid files in Sinusoidal (SIN, Level V006) projections (Neteler, 2005). The projection and the file format are not supported by most of the classical remote sensing/GIS programs. Therefore, a script was created to extract the individual bands stored inside HDF as plain GeoTiff files. In the same time, the images were repro- 
jected to Stereo 70 (EPSG: 31700). Further pre-processing steps after the reprojection comprise in sub-setting the MODIS scenes using study areas boundaries, convert the data into 8-bit unsigned integers ranging between 0 and 255 for facilitating further image processing, resample the $500 \mathrm{~m}$ bands to $250 \mathrm{~m}$ (nearest neighbour resampling method is used), stack the individual bands into multiband GeoTiffs, conversion from RGB to HSL color space (Saturation is part of some formulas), etc.

\section{Water detection from MODIS data}

The process of flood mapping can be complicated by several factors. First is that the water itself can have variable spectral qualities due to varying amounts of sediment it contains and algae (in the later phases of the Danube flood). This will affect the spectral response in some wavelengths more than others. Another problem is that the land surface surrounding the water is also variable (e.g. cultivated land, grasslands, forest, urban areas or snow). Optical sensors, such as MODIS, have other disadvantages as well. These include the inability to penetrate cloud cover and the fact that they cannot see water in a flooded forest environment. Although clear water has a low reflectance in Visible, NIR (Near Infrared) and SWIR (Short Wave Infrared), the presence of sediment can raise the reflectance in the visible and NIR wavelengths. This is most obvious in MODIS $250 \mathrm{~m}$ band $1(620-670 \mathrm{~nm})$; but it also affects MODIS $250 \mathrm{~m}$ band $2(841-876 \mathrm{~nm})$. Over recent decades, a number of techniques data have been developed to extract water from remote sensing data. We have included in our online platform the most relevant water indicators for usage in conjunction with MODIS data:

The Normalized Difference Water Index (NDWI) is using the reflected near infrared radiation and visible green light to highlight open waters from satellite images (McFeeters, 1996). NDWI is calculated using the following formula

$$
N D W I=(\text { Green }-N I R) /(\text { Green }+N I R)
$$

where Green $=$ Band 4 and NIR $=$ Band 2.

- The Modified Normalized Difference Water Index (MNDWI) is using the blue band to better extract shallow parts of the water body and to separate built-up structures from water feature $(\mathrm{Xu}, 2006)$. MDNWI is calculated as

$$
M N D W I=(\text { Blue }-N I R) /(\text { Blue }+N I R)
$$

where Blue $=$ Band 3 and NIR $=$ Band 2 .

- The Superfine Water Index (SWI) is derived by replacing the "Green" in the NDWI with the 'Saturation (Sat)' obtained from the HSV (Hue-Saturation-Value) transformation of the RGB composite made up of red (R), green (G), and blue (B) bands of the MODIS data (Sharma et al., 2015). The SWI provides very high contrast between the surface water and nonwater cover types including the snow and vegetation. SWI is calculated using the following formula

$$
S W I=(S a t-8 * N I R) /(S a t+7 * N I R)
$$

- The Normalized Difference Vegetation Index (NDVI) is one of the most commonly used vegetation indices. Despite the fact that is not designed for water extraction, water can be relatively easy separated from other features using appropriate thresholds. NDVI is calculated using the following formula $N D V I=(N I R-R e d) /(N I R+R e d)$,
$N D V I=(N I R-R e d) /(N I R+R e d)$

where $\operatorname{Red}=$ Band 1 and NIR = Band 2 (Rouse et al., 1973).

- The Simple Linear Iterative Clustering (SLIC) is not a classical index but an image segmentation technique from the computer vision domain. SLIC performs a local clustering of pixels in the 5-D space defined by the $\mathrm{L}, \mathrm{a}, \mathrm{b}$ values of the CIELAB color space and the $\mathrm{x}$, y pixel coordinates (Achanta et al., 2010).

A comparison of the results obtained with the listed indices in different phases of the flood is presented in Figure 2.

\section{Practical scenario for water mask extraction}

The extraction of the water mask from MODIS data can be performed by applying thresholds that separate water from other features by one of the indices or by a combination of indices/bands. Setting these thresholds required careful study of several cloud free scenes of the study area before the floods. Digital Elevation Models and topographical maps can be used to determine areas where flooding could be expected. Studying a set of images that covers the seasonal changes in river levels in the study area can lead to the identification of areas which are prone to flooding. Higher resolution cloud free images (such as ASTER or LANDSAT) can also be very useful in determining what is visible when looking at the lower resolution MODIS data. A practical approach of extracting the water mask with the help of NDVI is presented.

Generally, water is characterised by a low NDVI ratio, while green vegetation has high values, so a threshold of NDVI was very useful in discriminating flood water when it is inundating grasslands or crops (Craciunescu et al., 2009). However a low NDVI ratio can also result when both the pixel values for Red and Near IR are very high (since the ratio is proportional) - this means that clouds can have a low NDVI ratio. Some sedimentladen water had a very low NDVI ratio but rather high Near IR band 2 pixel values, (these were not as high as the Near IR band 2 pixel values for clouds). So the first step is to combine a NDVI threshold with a Near IR band 2 threshold that will exclude clouds but include sediment-laden water. Some flood water was not included, particularly if it was highly sedimentladen or in urban or non-vegetated areas which also have relatively low NDVI ratios. A second, higher NDVI threshold can be combined with a second, lower Near IR band 2 threshold to capture more water and eliminate the urban and non-vegetated areas which have similar NDVI ratios to the sediment-laden water. Sandbars in river channels are also eliminated this way. Finally there is water in swampy vegetated areas which has very low Near IR band 2 pixel values but relatively high NDVI ratio due to the vegetation. This can be included by a final low Near IR band 2 threshold. An example of a GRASS GIS band math equation follows:

$$
(a>0.18==b<9000)\|(a<0.32==b>3800)\| b>1900
$$

where $\mathrm{a}=N D V I(N D V I$ values range between -1 and 1$)$, and $\mathrm{b}$ $=$ Band 2 pixel value (MODIS band reflectance values are stored as 16-bit signed integer with a valid range of $-100-$ 16000).

\section{Validation methodology}

Result validation with independent sources of information is an important task but obtaining suitable validation data for his- 


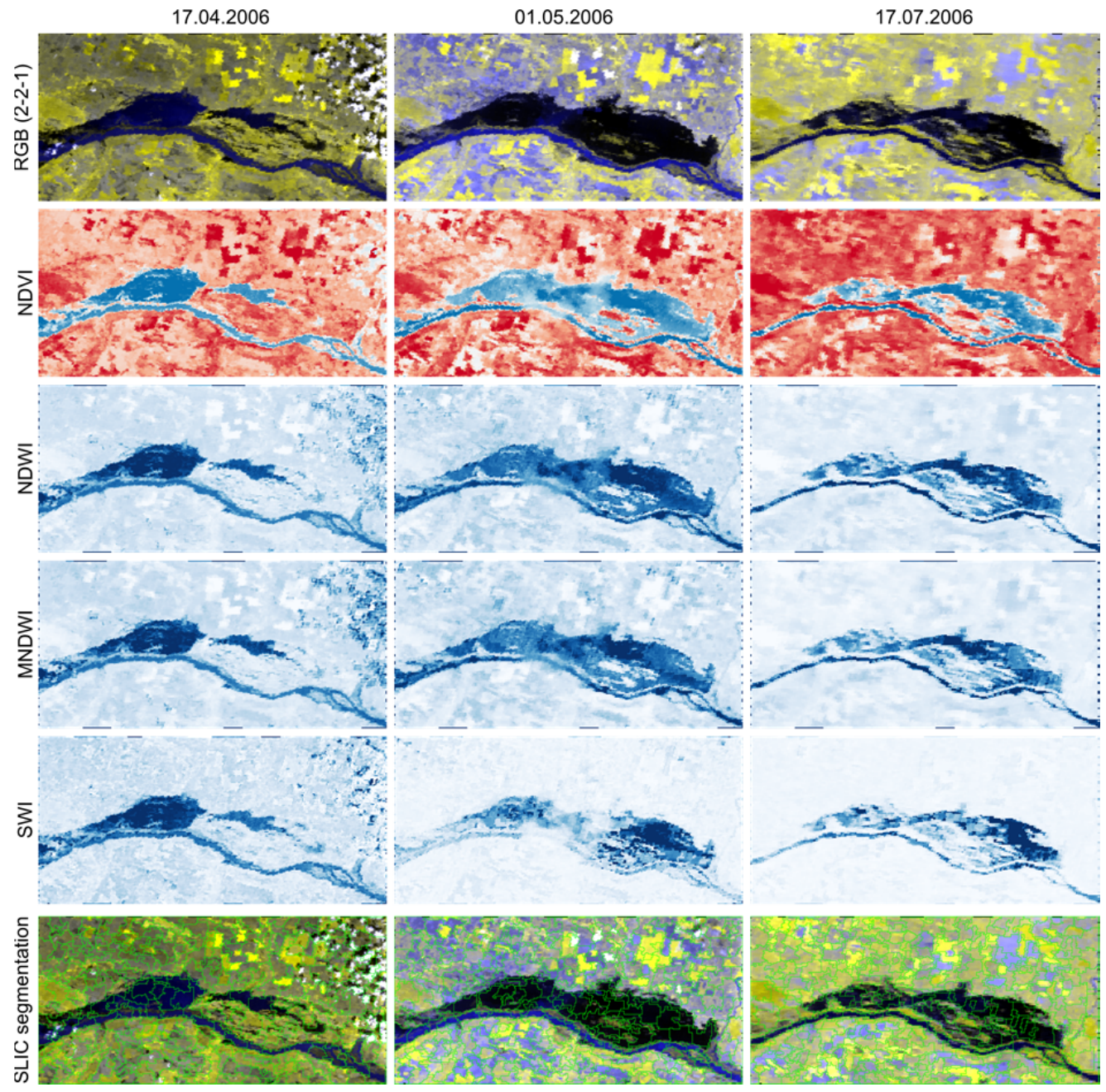

Fig. 2. Ghidici-Măceșu Sector: comparison plotting of the five water indices used by the platform for three moments in time. The RGB composite, used as reference, is obtained with MODIS band combination 2-2-1. The blue colour intensity shows the indices sensitivity to discriminate water from the MODIS data. Depending on the moment of the flood and the local conditions, each of the indices has strong and week points in water discrimination. For instance, NDVI and SWI are influenced by the soft haze that affects the central part of the flood on the scene from 01.05.2006. NDVI performs better in the early stages of the flood. In the later stages is affected by the eutrophication process in areas with shallow waters. The superpixeles of the SLIC segmentation are overestimating the flood extent.

torical floods extend in Romania is challenging because there is no official body in charge with flood extent in-situ measurements. However, for our study we were able to do intercomparisson analyses of the MODIS water extraction results with the one obtained from high resolution images from sensors like LANDSAT5/7, ASTER, FORMOSAT-2, SPOT5 and DMC. Though, obtaining high resolution data close to the moment of MODIS images acquisition is not simple. Due to the flood dynamics, every hour can bring important changes in the extent of the affected areas. That's why, for our study, ASTER data with ground resolutions of the VNIR, SWIR, and TIR spectral bands of $15 \mathrm{~m}, 30 \mathrm{~m}$, and $90 \mathrm{~m}$, respectively (Yamaguchi et al., 1998), proved to be the most suitable. The MODIS data was resampled (simple nearest neighbour method) and clipped to the pixel spacing and extent of the respective ASTER data. Each pixel of the ASTER imagery was checked against the classification result of the MODIS data and labelled into three classes according to the following criteria: flood detected by ASTER and MODIS, flood detected only in ASTER data and flood detected only in MODIS. According to overall quantitative analysis of the results in our test sites, the number of pixel classified as flood on MODIS is 7-9\% lower compared with the high resolution pixels from ASTER (Figure 3).

\section{RESULTS AND DISCUSSION}

The platform, created by National Meteorological Administration of Romania in the framework of the PNCDI2 GEODIM project, which offers services based on Open Geospatial Consortium standards for flood related data retrieval (Web Map Service - WMS, Web Coverage Service - WCS, Web Feature Service - WFS) and server-side processing (Web Processing Service - WPS), was used. The services were built upon open source solutions such as GeoServer, OpenLayers 3, PostgreSQL, GDAL, ZOO, etc. (Figure 4). The application is composed of several software modules/services. These are split into two categories: server-side modules/services and client side modules which are responsible for interaction with the user.

A typical usage scenario assumes the following steps: 1) the user is within the client functionality of the system and selects a date and a sector along the Danube (Figure 5); 2) the user inspects the MODIS data, the derived indices (see Sub-chapter Water detection from MODIS data) and the reference datasets; 3 ) the users select inputs (MODIS indices and/or bands) and the thresholds to be applied for water mask extraction; 4) the request is sent to the server side processing applications wrapped as a WPS call; 5) the process will perform the raster 

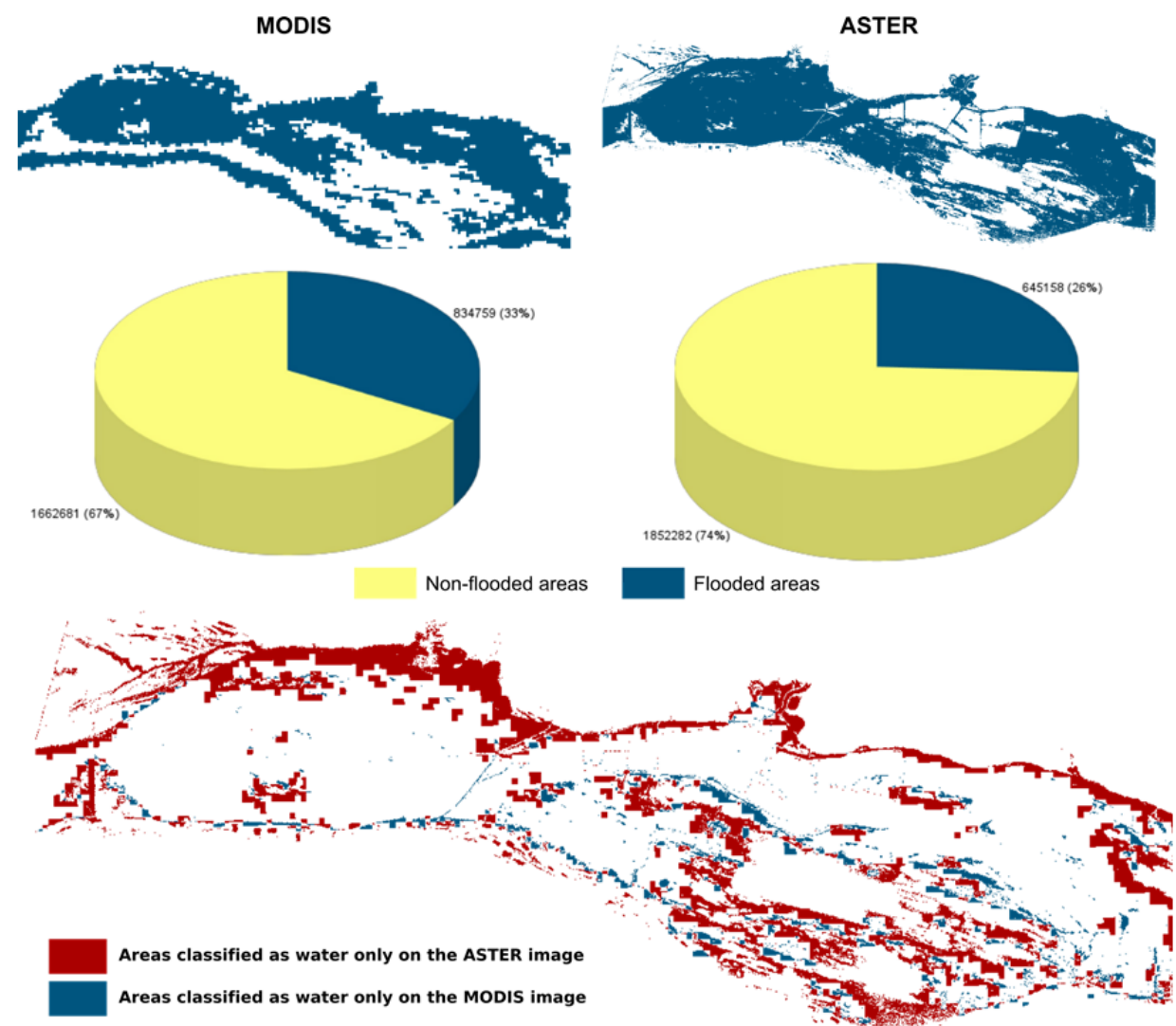

Fig. 3. Intercomparison of the MODIS and ASTER floodmasks (both images were acquired at the same moment, 09:26 UTC on 26.04.2006).
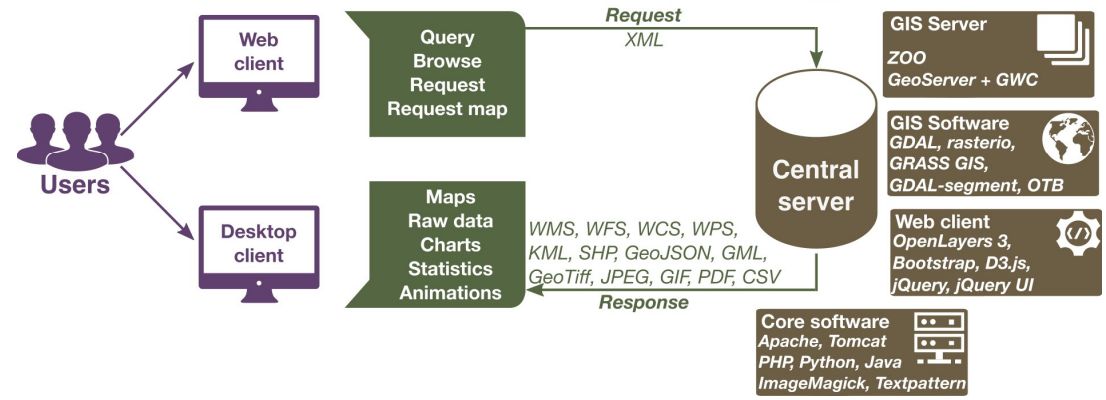

Fig. 4. Platform architecture.

algebra operation for the pixels within the area of interest (AOI); 6) the results (water mask) are sent back encoded in a standard file format; 7) the web client display the results as a map; 7) the user can recompute the water mask using adjusted thresholds or can request additional statistics (e.g. intersecting the water mask with other datasets like land cover/use).

The platform is capable to add new MODIS imagery in near real-time mode (approximately 2.5 hours after the observation at the spacecraft) via NASA Rapid Response facility.

Classic printable cartographic products were also generated and published online (Figure 6). The results can also be downloaded and used with more advanced spatial analysis and statistical programs. For example, Figure 7 presents the annual evolution $(2000-2014)$ of the NDVI mean values, for the 3 sectors analysed in this paper. As can be seen on the chart, in 2006 the NDVI values are lower, about 0.25 , than in other years, when the mean value is around 0.5 , meaning there was a very low photosynthetic activity in the areas due to the flood. Looking into the details in one of the area of interest (Figure 8), when analysing the NDVI evolution over the selected years, we can see how the flood that started in mid-April continued to affect the area up to mid-July, compromising the current and the next agricultural campaign. The use of such indices is very useful for researchers and the decision makers to better understand the effects of the flood in various parts of the affected areas. By studying the validation results along with other reference data (GIS layers, very high resolution aerial images, etc.) it was possible to observe that MODIS is underestimating the flood in areas with buildings, roads, irrigation channels, drainage channels and small/complex cultivated parcels. In contrast, MODIS results in an overestimation of the flood extent within the core of the floodplain, where ASTER is able to depict smaller nonflooded areas with higher elevations. Overall, the use of coarse resolution MODIS data is suitable to map relatively large floods in plain areas and not recommended for small floods in complex landscapes (built-up areas, small agriculture parcels 


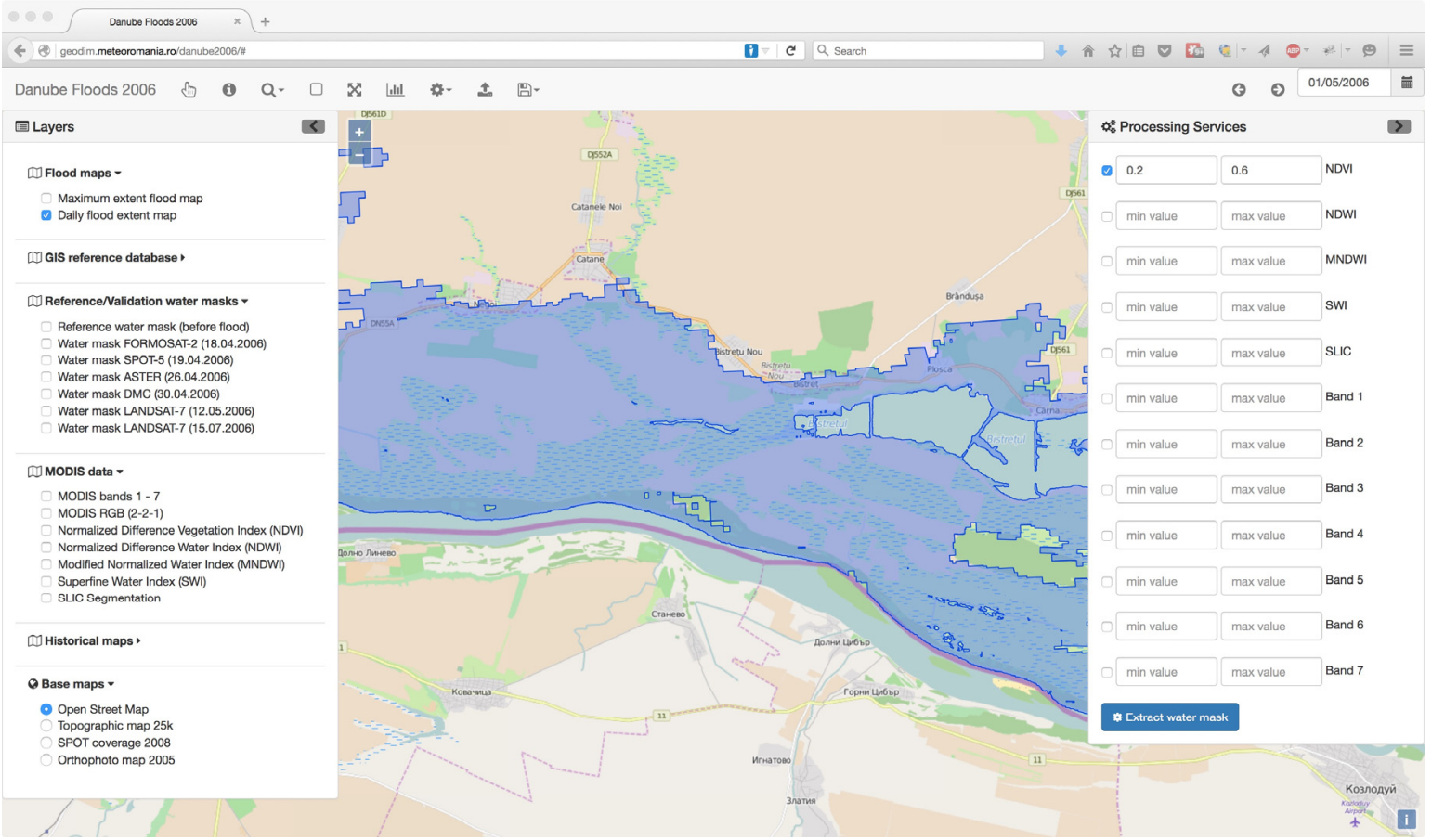

Fig. 5. Example of the webmapping client graphical interface.

\section{Danube River, sector Ghidici-Măceșu. Flood delineation map. Situation as of $\mathbf{1 6 . 0 5 . 2 0 0 6}$}

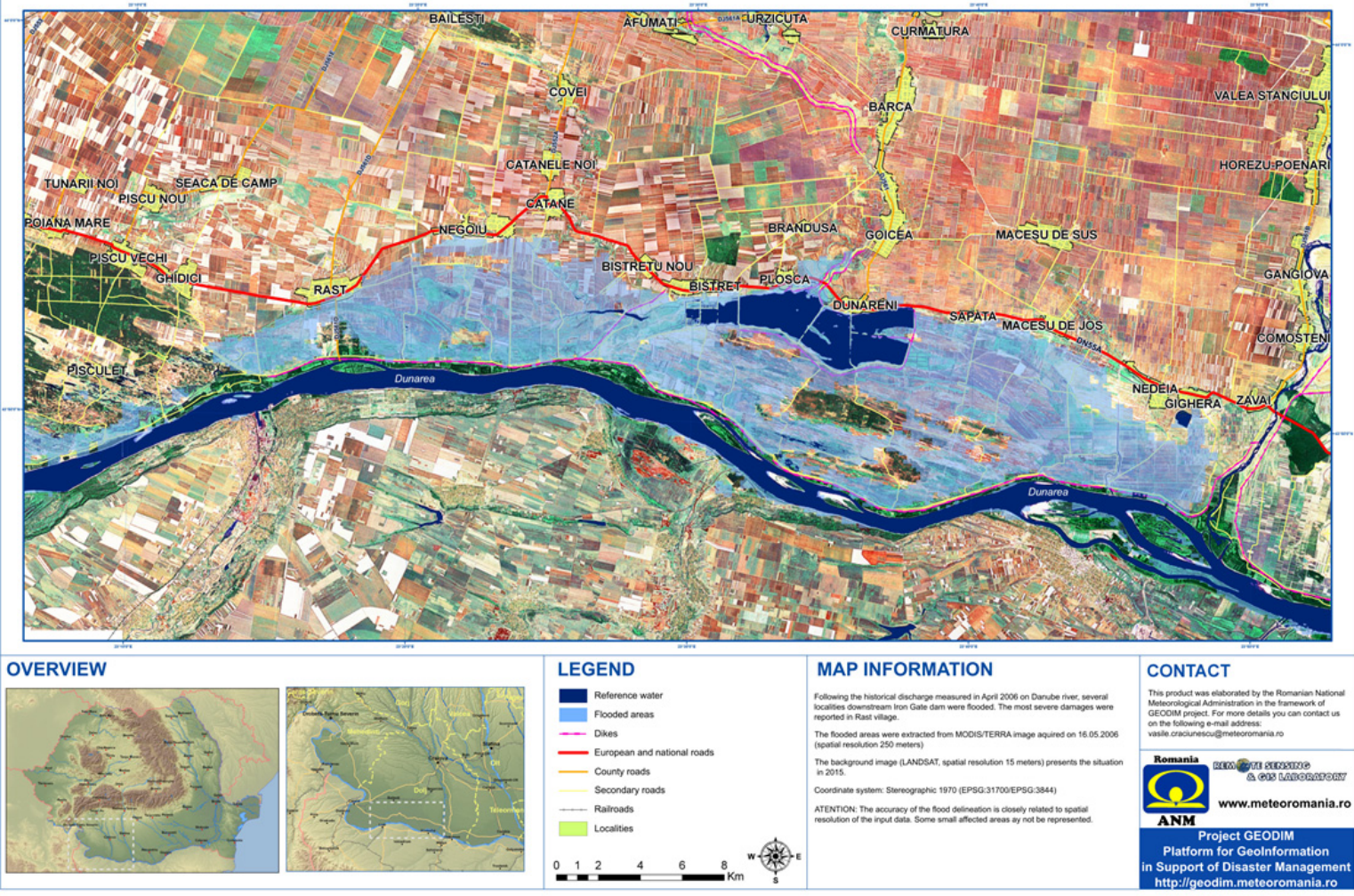

Fig. 6. Example: cartographic integration of the extracted water masks.

with different crops, forested areas, hilly or mountain areas, etc.). These results are consistent with the ones obtained in other studies (Martinis et al., 2013; Nigro et al., 2014; Ticehurst et al., 2015). Higher resolution, optical and SAR (Synthetic Aperture Radar) satellite images are able to provide more accurate information for flood delineation (Schuman et al., 2009). Nevertheless, MODIS is the only sensor able to provide global daily images, suitable to monitor and analyse large spatial and temporal plain floods like the one registered along the Danube in 2006. Cloud cover is always an issue when trying to map flood events using optical remote sensing data, especially during the rising stage of a flood event (Ticehurst et al., 2014). Again, the high temporal resolution of the MODIS images makes it relatively easy to find cloud free images for all the important moments of a large flood. 


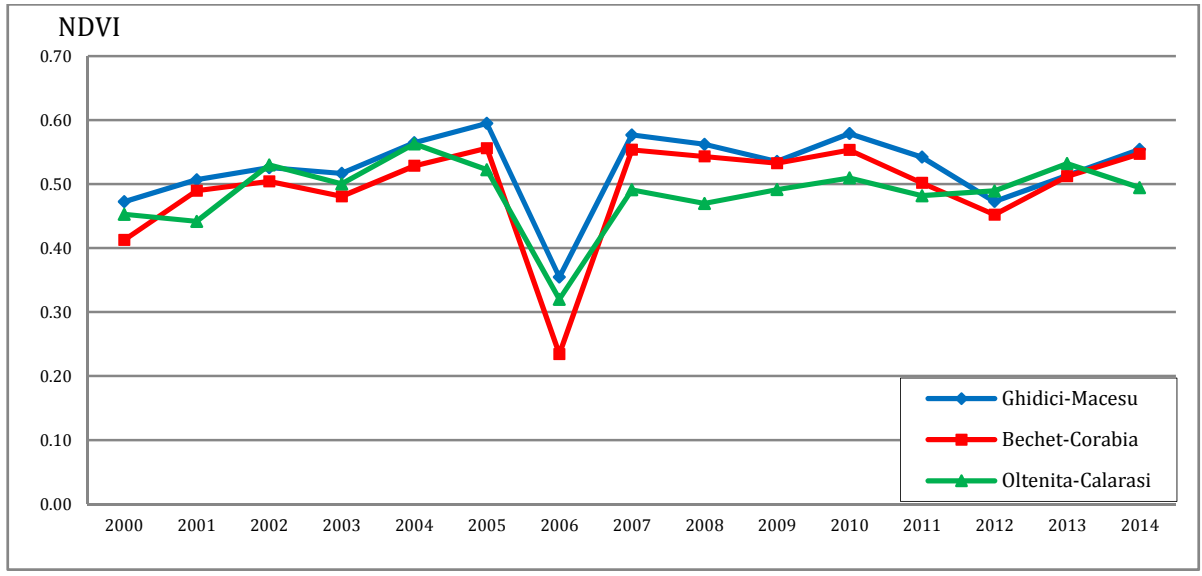

Fig. 7. NDVI mean values for the three flooded sectors along the Danube in 2006.

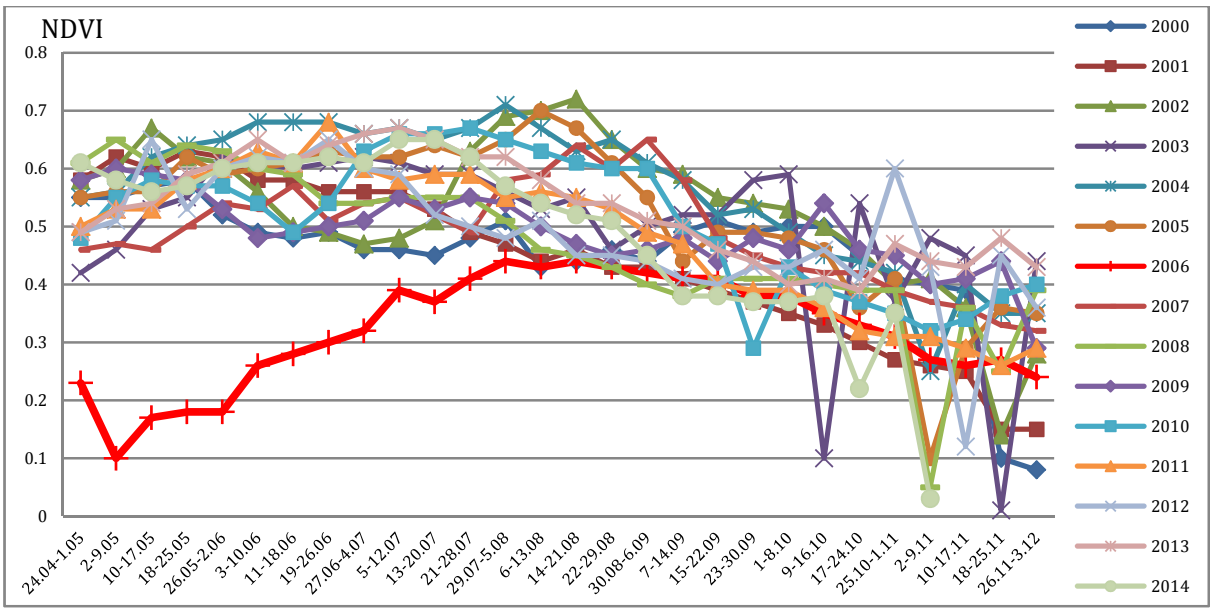

Fig. 8. NDVI evolution in 2006 for Oltenița-Călărași sector.

\section{CONCLUSIONS}

A new methodology for extracting areas affected by floods using MODIS satellite data was created. For testing purposes, a nine-months (April to December 2006) database, consisting of daily Terra MODIS images and relevant derived indices, covering the 2006 Danube flood most affected sectors, was created and published online via OGC compliant services. Researchers and users with appropriate rights can query the database and launch server-side processors that are able to extract the areas affected by the flood at a specified date and being able to adapt/calibrate the algorithm parameters for the local conditions. The results can be viewed as interactive maps in the webmapping client or accessed with desktop GIS clients via web services. The new methodology for flood mapping using MODIS satellite images and the developed online platform has the potential to improve flood management and to help the implementation of flood mitigation programs in Romania. The platform was successfully tested using Terra MODIS low spatial resolution satellite images (but high temporal resolution) for the 2006 historical Danube flood. However, the technology can be easily adapted for other regions and to use recent, higher resolution, satellite information such as the one provided by the EU Sentinel missions.

Acknowledgements. This work was supported by a grant of the Romanian National Authority for Scientific Research, CNDIUEFISCDI, "Platform for GeoInformation in Support of Disaster Management - GEODIM”, project number 202/2012.

\section{REFERENCES}

Achanta, R., Shaji, A., Smith, K., Lucchi, A., Fua, P., Süsstrunk, S., 2010. SLIC Superpixels, EPFL-REPORT149300. Available online at http://bit.ly/2b599VY. Last accessed: July 2016.

Amarnath, G., Rajah, A., 2015. An evaluation of flood inundation mapping from MODIS and ALOS satellites for Pakistan. Geomatics, Natural Hazards and Risk, 7, 5, 1526-1537.

Bessisa, J.L., Béquignonb, J., Mahmoodc, A., 2004. The International Charter "Space and Major Disasters" initiative. Acta Astronautica, 54, 3, 183-190.

Brakenridge, G., Anderson, E., Nghiem, S., Caquard, S., Shabaneh, T.B., 2003. Flood warnings, flood disaster assessments, and flood hazard reduction: The roles of orbital remote sensing. In: Proc. 30th Int. Symp. on Remote Sensing of Environment, International Center for Remote Sensing of Environment, Honolulu, Hawaii.

Coltin, B., McMichael, S., Smith, T., Fong, T., 2016. Automatic boosted flood mapping from satellite data. International Journal of Remote Sensing, 37, 5, 993-1015.

Constantinescu, Ș., Achim, D., Rus, I., Giosan, L., 2015. Embanking the Lower Danube: From natural to engineered floodplains and back. In: Hudson, P., Middelkoop, H. (Eds.): Geomorphic Approaches to Integrated Floodplain Management of Lowland Fluvial Systems in North America and Europe. Springer, New York, pp. 265-288. 
Copernicus EMS-Mapping, 2012. Copernicus Emergency Management Service - Mapping. Available online at http://emergency.copernicus.eu. Last accessed August 2016.

Craciunescu, V., Flueraru, C., Anderson, E., Nedelcu, I., Stancalie, G., Irimescu, A., 2009. Mapping and monitoring the 2005-2008 floods in Romania, using remote sensing techniques. Complexul Muzeal Bistrita Nasaud "Studii si Cercetari": Geology - Geography, Nr. 14, pp. 107-122.

Craciunescu, V., Flueraru, C., Stancalie, G., 2010. The usage of the historical cartographic datasets and the remote sensing data for the better understanding and mapping of the 2006 Danube floods in Romania. Acta Geodaetica et Geophysica Hungarica, 45, 112-119.

Crétaux, J-F., Bergé-Nguyen, M., Leblanc, M., Del Rio, R.A., Delclaux, F., Mognard, N., Lion, C., Pandey, R.K., Tweed, S., Calmant, S., Maisongrande, P., 2011. Flood mapping inferred from remote sensing data. In: Fifteenth International Water Technology Conference, IWTC-15 2011, International Water Technology Association, Alexandria, pp. 48-62.

European Commission, 2003. Best practices on flood prevention, protection and mitigation. Available online at http://bit.ly/1GCbDQX. Last accessed July 2016.

European Commission, 2011. Towards Better Environmental Options for Flood risk management Available online at http://bit.ly/2bbX5zG. Last accessed July 2016.

European Commission, 2014. Natural Water Retention Measures, Technical Report - 2014 - 082, ISBN 978-92-7944497-5, Available online at http://bit.ly/2aIysMz. Last accessed August 2016.

GLCF MODIS Flood Maps, 2008. Global Land Cover Facility MODIS Flood Maps. Available online at http://glcf.umd.edu/data/flood. Last accessed August 2016.

Islam, A.K., Bala, S.K., Haque, A., 2010. Flood inundation map of Bangladesh using MODIS surface reflectance data. Journal of Flood Risk Management. 3, 3, 210-222.

Jensen, J.R., 2015. Introductory Digital Image Processing: A Remote Sensing Perspective. Pearson. ISBN-13: 9780134058160

Kawak, Y., Iwami, Y., 2014. Nationwide flood inundation mapping in Bangladesh by using modified land surface water index. ASPRS 2014 Annual Conference Louisville, Kentucky, 2014. Available online at http://bit.ly/2aRGRLm. Last accessed August 2016.

Kugler, Z., De Groeve, T., 2007. The Global Flood Detection System. JRC Scientific and Technical Reports. Available online at http://bit.ly/2aD27mK. Last accessed August 2016.

Martinis, S., Twele, A., Strobl, C., Kersten, J., Stein, E., 2013. A multi-scale flood monitoring system based on fully automatic MODIS and TerraSAR-X processing chains. Remote Sensing, 5, 11, 5598-5619.

McFeeters, S.K., 1996. The use of the Normalized Difference Water Index (NDWI) in the delineation of open water features. Int. J. Remote Sens., 17, 1425-1432.

McIntyre, N., Thorne, C. (Eds.), 2013. Land use management effects on floods flows and sediments - guidance on prediction. CIRIA, ISBN: 978-0-86017-722-7.

Nichersu, I., 2009. Ecological and Economical Restoration of Danube Floodplain. Available online at http://bit.ly/2bbXoua. Last accessed August 2016.

Neteler, M., 2005. Time Series Processing of MODIS Satellite Data for Landscape Epidemiological Applications. International Journal of Geoinformatics, 1, 1, 133-138.

Nigro, J., Slayback, D., Policelli, F., Brakenridge, G.B., 2014. NASA/DFO MODIS Near Real Time (NRT) Global Flood Mapping Product Evaluation of Flood and Permanent Water
Detection. Available online at http://go.nasa.gov/2aS2WuG. Last accessed July 2016.

Park, J., Kwak, Y., 2011. Determination of inundation area based on flood hazard for a global water risk assessment. In: Blöschl, G., Takeuchi, K., Jain, S., Farnleitner, A., Schumann, A. (Eds.): Risk in Water Resources Management. IAHS Publ. 347, Wallingford, pp. 61-64.

Phuong, D.D., Yuei-An, L., Chih-Wei, C., 2015. Detection of flood inundation regions with Landsat/MODIS synthetic data. In: Int. Symp. on Remote Sensing 2015, Taiwan. Available online at http://bit.ly/2b3LIOg. Last accessed August 2016.

Romanian Ministry of Environment and Water Management, 2006. Report on 2006 hydrological events. Available online at http://bit.ly/2b3M8nE. Last accessed October 2015.

Rouse, J.W., Haas, R.H., Schell, J.A., Deering, D.W., 1973. Monitoring vegetation systems in the Great Plains with ERTS. In: Proc. 3rd ERTS Symp., NASA SP-351 I, pp. 309-317.

Schuman, G., Bates, P.D., Horritt, M.S., Matgen, P., Pappenberger, F., 2009. Progress in integration of remote sensingderived flood extent and stage data and hydraulic models. Rev. Geophys., 47, RG4001. doi: 10.1029/2008RG000274.

Sharma, R.C., Tateishi, R., Hara, K., Nguyen, L.V., 2015. Developing Superfine Water Index (SWI) for Global Water Cover Mapping Using MODIS Data. Remote Sens., 7, 13807-13841.

Sun, D.L., Yu, Y.Y., 2010. Deriving water fraction and flood map with the eos/modis data using regression tree approach. ISPRS TC VII Symposium - 100 Years ISPRS, IAPRS, Vol. XXXVIII, Part 7B.

Ticehurst, C.J., Chen, Y., Karim, F., Dutta, D., Gouweleeuw, B., 2013. Using MODIS for mapping flood events for use in hydrological and hydrodynamic models: Experiences so far. 20th International Congress on Modelling and Simulation, Adelaide, Australia, 2013. Available online at http://bit.ly/2arLm2E. Last accessed August 2016.

Ticehurst, C., Guerschman, J.P., Chen, Y., 2014. The strengths and limitations in using the daily MODIS open water likelihood algorithm for identifying flood events. Remote Sens., 6, 11791-11809.

Ticehurst, C., Dutta, D., Vaze, J., 2015. A comparison of Landsat and MODIS flood inundation maps for hydrodynamic modelling in the Murray Darling Basin. In: Proc. 21st International Congress on Modelling and Simulation, Gold Coast, Australia. Available online at http://bit.ly/2aD276b. Last accessed July 2016.

UN SPIDER, 2006. United Nations platform for space-based information for disaster management and emergency response. Available online at http://www.un-spider.org. Last accessed August 2016

Wachter, K., 2008. The Analysis of the Danube Floods 2006. Available online at http://bit.ly/2arFM01. Last accessed July 2016.

$\mathrm{Xu}, \mathrm{H} ., 2$ 2006. Modification of normalised difference water index (NDWI) to enhance open water features in remotely sensed imagery. Int. J. Remote Sens., 27, 14, 3025-3033.

Yamaguchi, Y., Kahle, A.B., Tsu, H., Kawakami, T., Pniel, M., 1998. Overview of Advanced Spaceborne Thermal Emission and Reflection Radiometer (ASTER). IEEE Trans. Geosci. Remote Sens., 36, 4, 1062-1071.

Received 15 December 2015 Accepted 10 August 2016 